\title{
Analisis Perhitungan, Pemotongan, Dan Pelaporan Pajak Penghasilan Pasal 23 Pada PT. Banyu Biru Sentosa
}

\author{
Julianto $^{1)}$ \\ Etty Herijawati ${ }^{2)}$ \\ Universitas Buddhi Dharma, Indonesia, Banten
}

\begin{abstract}
ABSTRAK
Penelitian ini dilakukan pada PT. Banyu Biru Sentosa yang merupakan sebuah perusahaan yang bergerak di bidang eksportir barang, khususnya adalah perusahaan yang melakukan penjualan koral (terumbu karang) beserta ikan hias air laut ke luar negeri. Adapun tujuan penelitian ini adalah untuk mengetahui bagaimana perhitungan pemotongan dan pelaporan pajak penghasilan pasal 23 atas penggunaan jasa perantara atau keagenan (freight forwarder) dan untuk mengetahui apakah perhitungan, pemotongan dan pelaporan pajak penghasilan pasal 23 atas penggunaan jasa perantara dan keagenan (freight forwarder) sudah sesuai dengan peraturan perpajakan di Indonesia.

Sumber data yang dipakai dalam penelitian ini adalah data primer dan data sekunder. Data primer diperoleh dengan menggunakan daftar pertanyaan berupa wawancara dengan divisi accounting yang sudah terstruktur dengan tujuan untuk mengumpulkan informasi dari perusahaan di PT. Banyu Biru Sentosa. Sedangkan data sekunder diperoleh dengan menggumpulkan data-data yang ada di perusahaan dengan melakukan dokumentasi terhadap faktur-faktur maupun bukti potong pajak penghasilan pasal 23 yang nantinya akan diteliti.

Berdasarkan hasil analisis yang dilakukan maka diperoleh kesimpulan bahwa PT. Banyu Biru Sentosa masih belum sesuai dengan peraturan perpajakan yang berlaku di Indonesia dalam melakukan perhitungan, pemotongan dan pelaporan pajak penghasilan pasal 23 atas penggunaan jasa perantara atau keagenan (freight forwarder).
\end{abstract}

Kata Kunci : Perhitungan, Pemotongan, Pelaporan Pajak Penghasilan Pasal 23 


\begin{abstract}
This research was conducted in the PT. Banyu Biru Sentosa called a corporation in the area of goods exporters, especially on the sells coral (coral reefs) and ocean fish overseas. As far as the goal of this study is to find out how math is done, article 23 income tax cuts and reporting on agency or agency (freight forwarder) use and to find out if calculations, revenue cuts and reporting section 23 at intermediate services or agency (freight forwarder) are now consistent with tax regulations in Indonesia.

Sources of data used in this study are primary and secondary data. Primary data gained using a list of questions of interviews with structured accounting divisions in order to gather information from the company at PT. Banyu Biru Sentsosa. Secondary data is obtained by collecting the records within the company by documenting both invoices and evidence of entry-level 23 income tax to be investigated.

Based on the right analysis, it is concludedthat uterized PT. Banyu Biru Sentosa is still not as appropriate as the Indonesian tax authority for calculating, deductions and tax reporting sections 23 for use of agency or bureau (freight forwarder).
\end{abstract}

Keywords : Calculations, Deductions, Article 23 Income Tax Reporting. 


\section{PENDAHULUAN}

Indonesia merupakan suatu negara yang sedang memfokuskan pembangunan disegala bidang termasuk bidang ekonomi. Perekonomian suatu negara dapat menentukan keberlangsungan perkembangan dan majunya suatu negara. Untuk mensukseskan pembangunan tersebut peranan penerimaan dalam negeri sangat penting yaitu dari sektor pajak. Fungsi utama dari pajak adalah untuk meningkatkan pendapatan suatu negara, gunanya adalah untuk membiayai pengeluaran penting pada barang dan jasa yang disediakan oleh pemerintah (Okoye \& Ezejiofor, 2014).

Data Kementerian Keuangan Republik Indonesia, pendapatan dari sektor pajak, dengan realisasi penerimaan sampai dengan 31 Desember 2016 mencapai Rp.1,105 triliun atau 81,54\%. Dengan demikian, pajak merupakan sumber penerimaan negara yang paling utama dan yang paling besar pada APBN. Pajak digunakan sebagai salah satu usaha yang digunakan oleh pemerintah untuk mewujudkan kemandirian suatu bangsa atau negara dalam pembiayaan pembangunan yang berguna bagi kepentingan bersama (Khasanah, 2014).

Penerimaan pajak penghasilan $(\mathrm{PPh})$ merupakan salah satu penerimaan terbesar bagi suatu negara. Pajak penghasilan atau yang sering disebut dengan PPh yaitu pajak yang dikenakan subjek pajak penghasilan yang diterima atau diperolehnya dalam tahun pajak (Resmi, 2014:74). Definisi penghasilan menurut pasal 4 UU PPh adalah setiap tambahan kemampuan ekonomis yang diterima atau diperoleh wajib pajak, baik yang berasal dari Indonesia, yang dapat dipakai sebagai konsumsi atau menambah kekayaan wajib pajak yang bersangkutan, dengan nama maupun dalam bentuk apapun.

Salah satu pajak penghasilan yaitu pajak penghasilan pasal 23. Pajak penghasilan pasal 23 merupakan pajak yang dipotong atas penghasilan yang diterima atau diperoleh wajib pajak dalam negeri serta bentuk usaha tetap dengan nama dan dalam bentuk apapun yang berasal dari modal, penyerahan jasa, atau penyelenggaraan kegiatan selain yang telah dipotong $\mathrm{PPh}$ pasal 21; meliputi dividen, royalti, hadiah dan penghargaan, sewa, penghasilan sehubungan dengan penggunaan harta, dan imbalan jasa tertentu (Bahar, 2013). Dasar hukum pengenaan pajak penghasilan pasal 23 pada mulanya adalah Undang-undang Nomor 7 Tahun 1983, namun demikian undang-undang ini terus mengalami perubahan. Perubahan terakhir yang berlaku saat ini adalah Undang-Undang Nomor 36 Tahun 2008. Pajak penghasilan sudah beberapa kali mengalami perubahan undang-undang. Hal ini dimaksudkan untuk meningkatkan fungsi dan peranan perpajakan dalam rangka mendukung suatu kebijakan pembangunan nasional, khusunya dibidang ekonomi.

Pada dasarnya pemotongan $\mathrm{PPh}$ Pasal 23 sering terjadi kesalahan dalam proses perhitungan yang dapat mengakibatkan kekurangan atas jumlah pajak yang seharusnya disetor ke negara. Kekurangan tersebut dapat mengakibatkan kerugian baik bagi wajib pajak dikarenakan adanya sanksi dari kantor pajak maupun bagi negara karena berkurangnya penerimaan dari sektor pajak.

Perhitungan merupakan suatu prosedur yang dilalukan oleh seseorang maupun sebuah instansi guna menentukan besarnya nilai yang terdapat pada suatu barang maupun suatu benda.

Pemotongan merupakan suatu cara yang dilakukan oleh seseorang maupun sebuah instansi guna mengurangi besarnya sebuah nilai yang terdapat pada suatu hal maupun kejadian, dalam hal ini berkaitan terhadap transaksi yang dilakunan.

Pelaporan merupakan suatu cara yang dilakukan seseorang maupun sebuah instansi dalam memenuhi kewajibannya sebagai wajib pajak guna turut serta dalam melaporkan hasil pekerjaannya yang telah dilakukan. 
PT. Banyu Biru Sentosa merupakan Perusahaan yang bergerak di bidang eksportir barang, khususnya adalah perusahaan yang melakukan penjualan koral (terumbu karang) beserta ikan hias air laut ke luar negeri. PT. Banyu Biru Sentosa berlokasi di Jalan Bungur I No.2, RT. 014 / RW. 01, Kebayoran Lama, Jakarta Selatan, Daerah Khusus Ibukota Jakarta 12240.

Sebagai perusahaan global yang terus berusaha untuk memaksimalkan penjualan ekspor. Perusahaan ini mampu untuk melaksanakan kegiatan penjualannya yang berukuran besar dimana membutuhkan mitra kerja untuk setiap aktivitas. Tuntutan permintaan akan penjualan yang banyak mengharuskan perusahaan mencari jasa perantara atau keagenan yang kompetitif guna memaksimalkan kinerja atas permintaan tersebut.

PT. Banyu Biru Sentosa itu sendiri merupakan suatu wajib pajak badan yang banyak mengenakan PPh Pasal 23. Dalam pelaksanaannya terbagi menjadi tiga kelompok yaitu perhitungan, pemotongan dan pelaporan. Berikut merupakan ringkasan data yang dimiliki PT. Banyu Biru Sentosa :

Tabel I.1

Perhitungan, Pemotongan dan Pelaporan Pajak Penghasilan pasal 23 PT. Banyu Biru Sentosa.

\begin{tabular}{|c|c|c|c|c|c|c|c|}
\hline No & $\begin{array}{c}\text { Tgl } \\
\text { Transaksi }\end{array}$ & $\begin{array}{c}\text { Agen } \\
(\mathrm{PT})\end{array}$ & DPP & Jasa & Tarif & $\begin{array}{c}\text { Besar } \\
\text { Pemotongan }\end{array}$ & $\begin{array}{c}\text { Tgl } \\
\text { Lapor }\end{array}$ \\
\hline 1 & $08 / 10 / 18$ & ATT & Rp. 25.258.650 & Rp. - & $2 \%$ & Rp. 505.173 & $05 / 03 / 19$ \\
\hline 2 & $05 / 11 / 18$ & ATT & Rp. 30.918.150 & Rp. - & $2 \%$ & Rp. 618.363 & $05 / 03 / 19$ \\
\hline 3 & $04 / 10 / 18$ & HMP & Rp. 39.650.800 & Rp. - & $2 \%$ & Rp. 793.016 & $11 / 11 / 19$ \\
\hline 4 & $25 / 11 / 18$ & HMP & Rp. 55.378.890 & Rp. 528.000 & $2 \%$ & Rp. 10.560 & $05 / 03 / 19$ \\
\hline 5 & $11 / 10 / 18$ & 3SS & Rp. 22.822.170 & Rp. - & $2 \%$ & Rp. $456.443,40$ & $11 / 11 / 18$ \\
\hline 6 & $19 / 11 / 18$ & 3SS & Rp. 14.326.800 & Rp. - & $2 \%$ & Rp. 286.536 & $11 / 01 / 19$ \\
\hline 7 & $12 / 11 / 18$ & RMA & Rp. 56.810.400 & Rp. 1.143 .000 & $2 \%$ & Rp. 22.860 & $11 / 01 / 19$ \\
\hline 8 & $11 / 01 / 19$ & RMA & Rp. 48.890.645 & Rp. 1.045 .000 & $2 \%$ & Rp. 20.910 & $05 / 03 / 19$ \\
\hline
\end{tabular}

Sumber : PT. Banyu Biru Sentosa

Menurut data diatas untuk perhitungan, pemotongan dan pelaporan PPh Pasal 23 pada PT. Banyu Biru Sentosa tersebut belum dilakukan dengan benar sepenuhnya dan kemungkinan terdapat kesalahan dalam memotong dan melaporkan besarnya jumlah $\mathrm{PPh}$ Pasal 23.

Untuk perhitungan, tarif yang digunakan yaitu sebesar 2 persen (2\%) sudah sesuai dengan peraturan perpajakan yang ada di Indonesia.

Namun untuk pemotongan masih belum mengikuti peraturan yang ada dalam pengimplementasiannya PT. Banyu Birus Sentosa mengenakan sebesar 2\% dari dasar pengenaan pajak (DPP) maupun dari jasanya saja. Namun berdasarkan undang - undang perpajakan No. 36 tahun 2008 besarnya potongan pajak penghasilan pasal 23 yaitu sebesar $2 \%$ atas jasanya saja.

Untuk pelaporannya, PT. Banyu Biru Sentosa selalu melewati batas ketentuan yang di berikan oleh kantor pajak yaitu tanggal 20 bulan berikutnya.

\section{METODE PENELITIAN}

\section{Jenis Penelitian}

Jenis Penelitian ini menggunakan pendekatan deskriptif. Karena penelitian ini disajikan untuk mendeskripsikan suatu fenomena atau suatu gejala. Pendekatan deskriptif adalah salah satu jenis penelitian yang bertujuan untuk menyajikan gambaran lengkap mengenai setting sosial atau dimaksudkan untuk eksplorasi dan klarifikasi mengenai suatu fenomena atau kenyataan sosial. 


\section{Objek Penelitian}

Penulis melakukan penelitian mengenai $\mathrm{PPh}$ Pasal 23 dengan objek penelitian pada departemen accounting PT. Banyu Biru Sentosa.

\section{Jenis dan Sumber Data Jenis Data}

Jenis data yang digunakan dalam penelitian ini adalah data kuantitatif dan kualitatif yaitu berupa data primer dan data sekunder yang diperoleh secara langsung dari perusahaan dimana penulis melakukan penelitian serta dari agensi penyedia jasa perantara atau kagenan, yaitu berupa wawancara dan dokumentasi kepada pihak-pihak terkait yang berhubungan dengan penelitian ini.

Data kuantitatif merupakan data yang berbentuk angka atau bilangan. Sesuai dengan bentuknya, data kuantitatif dapat diolah atau dianalisis menggunakan teknik perhitungan matematika atau statistika.

Data kualitatif merupakan data yang berbentuk kata-kata, bukan dalam bentuk angka. Data kualitatif diperoleh melalui berbagai macam teknik pengumpulan data misalnya wawancara, analisis dokumen, diskusi terfokus, atau observasi yang telah dituangkan dalam catatan lapangan (transkrip).

\section{Sumber Data}

Sumber data yang dipakai dalam penelitian ini adalah data primer dan data sekunder. Data primer adalah sumber data yang diperoleh secara langsung dari sumber asli (tidak melalui perantara) yang dikumpulkan oleh peneliti dengan tujuan tertentu sesuai dengan kebutuhan.

Data primer diperoleh dengan menggunakan daftar pertanyaan berupa wawancara yang sudah terstruktur dengan tujuan untuk mengumpulkan informasi dari PT. Banyu Biru Sentosa yang dalam hal ini menjadi responden penelitian ini.

Data sekunder adalah data yang diperoleh lewat pihak lain, tidak langsung diperoleh oleh peneliti dari subjek penelitiannya. Data sekunder ini disebut juga dengan data tangan kedua. Data sekunder biasanya berwujud data dokumentasi atau data laporan yang telah tersedia .

\section{Teknik Pengumpulan Data}

Teknik pengumpulan data merupakan langkah yang paling strategis dalam sebuah penelitian, sebab tujuan utama dari penelitian adalah mendapatkan data yang akurat, sehingga tanpa mengetahui teknik pengumpulan data peneliti tidak akan mendapatkan data yang memenuhi standar yang ditetapkan (Sugiyono 2016, 224). Teknik pengumpulan data yang digunakan dalam penelitian ini adalah dengan menggunakan metode wawancara, dan dokumentasi.

1. Wawancara

Wawancara merupakan percakapan dengan maksud tertentu, yang dilakukan oleh dua pihak yaitu pewawancara (interviewer) yang mengajukan pertanyaan dan yang diwawancarai (interviewee) yang memberikan jawaban atas pertanyaan yang telah diberikan (Moleong 2014, 186).

2. Dokumentasi

Dokumentasi merupakan catatan peristiwa yang sudah berlalu, dapat berbentuk tulisan, gambar, atau karya-karya monumental dari seseorang. Dokumen yang berbentuk tulisan misalnya catatan harian, sejarah kehidupan, biografi, peraturan dan kebijakan. Dokumen yang berbentuk gambar misalnya foto, gambar hidup, skesta dan lain-lain. Dokumen yang berbentuk karya misalnya karya seni yang dapat berupa gambar, patung, film dan 
sebagainya. Studi dokumen merupakan pelengkap dari penggunaan metode observasi dan wawancara (Sugiyono 2016, 240).

\section{Teknik Analisis Data}

Teknik analisis data yang digunakan di kelompokkan menjadi 3 bagian diantaranya adalah sebagai berikut :

1. Perhitungan

Tarif perhitungan $\mathrm{PPh}$ pasal 23 sebesar $2 \%$.

2. Pemotongan

Tarif pemotongan $\mathrm{PPh}$ pasal $23=2 \%$ x nilai jasa yang diberikan.

3. Pelaporan

Batas akhir pelaporan PPh pasal 23 tidak boleh melewati tanggal 20 bulan takwim.

\section{HASIL PENELITIAN}

Perhitungan Pajak Penghasilan Pasal 23 atas Jasa Perantara atau Keagenan (Freight Forwarder) pada PT. Banyu Biru Sentosa.

\begin{tabular}{|c|c|c|c|c|c|c|c|}
\hline No & $\begin{array}{c}\text { Tanggal } \\
\text { Transaksi }\end{array}$ & $\begin{array}{c}\text { Nama } \\
\text { Agen } \\
(\mathrm{PT})\end{array}$ & DPP & PPN & Jasa & Tarif & Besar Potongan \\
\hline 1 & $03 / 10 / 2018$ & ATT & Rp. 66.444 .730 & Rp. 664.447,30 & Rp. - & $2 \%$ & Rp. 1.328.894,60 \\
\hline 2 & $08 / 10 / 2018$ & ATT & Rp. 25.258 .650 & Rp. 252.586,50 & Rp. - & $2 \%$ & Rp. 505.173 \\
\hline 3 & $10 / 10 / 2018$ & ATT & Rp. 34.318 .200 & Rp. 343.182 & Rp. - & $2 \%$ & Rp. 686.364 \\
\hline 4 & $17 / 10 / 2018$ & ATT & Rp. $\quad 61.433 .010$ & Rp. 614.330,10 & Rp. - & $2 \%$ & Rp. 1.228.660,20 \\
\hline 5 & $18 / 10 / 2018$ & ATT & Rp. 20.166 .170 & Rp. 201.661,70 & Rp. - & $2 \%$ & Rp. $403.323,40$ \\
\hline 6 & $24 / 10 / 2018$ & ATT & Rp. 36.195 .950 & Rp. 361.959.50 & Rp. - & $2 \%$ & Rp. 723.919 \\
\hline 7 & $27 / 10 / 2018$ & ATT & $\begin{array}{ll}\text { Rp. } & 4.370 .000 \\
\end{array}$ & Rp. 43.700 & Rp. - & $2 \%$ & Rp. 87.400 \\
\hline 8 & $30 / 10 / 2018$ & ATT & $\begin{array}{ll}\text { Rp. } & 13.671 .702\end{array}$ & Rp. 136.717,02 & Rp. - & $2 \%$ & Rp. 273.434,04 \\
\hline 9 & $31 / 10 / 2018$ & ATT & Rp. 53.046 .050 & Rp. 530.460,50 & Rp. - & $2 \%$ & Rp. 1.060.921 \\
\hline 10 & $04 / 10 / 2018$ & HMP & Rp. 39.650 .800 & Rp. 396.508 & Rp. - & $2 \%$ & Rp. 793.016 \\
\hline 11 & $09 / 10 / 2018$ & HMP & Rp. 50.534 .200 & Rp. 505.342 & Rp. - & $2 \%$ & Rp. 1.010.684 \\
\hline 12 & $09 / 10 / 2018$ & HMP & Rp. 31.687 .750 & Rp. 316.878 & Rp. - & $2 \%$ & Rp. 633.755 \\
\hline 13 & $19 / 10 / 2018$ & HMP & Rp. 23.246.208 & Rp. 232.462 & Rp. - & $2 \%$ & Rp. 464.924,16 \\
\hline 14 & $23 / 10 / 2018$ & HMP & Rp. 31.807 .575 & Rp. 318.076 & Rp. - & $2 \%$ & Rp. 636.151,50 \\
\hline 15 & $30 / 10 / 2018$ & HMP & Rp. 42.926 .625 & Rp. 429.266 & Rp. - & $2 \%$ & Rp. 858.532,50 \\
\hline 16 & $11 / 10 / 2018$ & $3 \mathrm{SS}$ & Rp. 22.822 .170 & Rp. $228.221,70$ & Rp. - & $2 \%$ & Rp. $456.443,40$ \\
\hline 17 & $18 / 10 / 2018$ & $3 \mathrm{SS}$ & Rp. 19.818 .464 & Rp. 198.184,64 & Rp. - & $2 \%$ & Rp. 396.369,28 \\
\hline 18 & $03 / 10 / 2018$ & RMA & Rp. 99.160 .065 & Rp. 991.601 & Rp. 2.038.500 & $2 \%$ & Rp. 40.770 \\
\hline 19 & $15 / 10 / 2018$ & RMA & Rp. 56.128 .415 & Rp. 561.284 & Rp. 1.153 .500 & $2 \%$ & Rp. 23.070 \\
\hline 20 & $22 / 10 / 2018$ & RMA & Rp. 126.022.700 & Rp. 1.260.227 & Rp. 2.536.500 & $2 \%$ & Rp. 50.730 \\
\hline 21 & $05 / 11 / 2018$ & ATT & Rp. 30.918.150 & Rp. $309.181,50$ & Rp. - & $2 \%$ & Rp. 618.363 \\
\hline 22 & $07 / 11 / 2018$ & ATT & Rp. 31.099.700 & Rp. 310.997 & Rp. - & $2 \%$ & Rp. 621.994 \\
\hline 23 & $08 / 11 / 2018$ & ATT & Rp. 11.058.528 & Rp. 110,585,28 & Rp. - & $2 \%$ & Rp. 221.170,56 \\
\hline 24 & $13 / 11 / 2018$ & ATT & Rp. 12.542 .720 & Rp. $125.427,20$ & Rp. - & $2 \%$ & Rp. $250.854,40$ \\
\hline 25 & $14 / 11 / 2018$ & ATT & Rp. 51.511.850 & Rp. 515.118,50 & Rp. - & $2 \%$ & Rp. 1.030.237 \\
\hline 26 & $21 / 11 / 2018$ & ATT & Rp. 34.318.700 & Rp. 343.187 & Rp. - & $2 \%$ & Rp. 686.374 \\
\hline 27 & $13 / 11 / 2018$ & HMP & Rp. 30.252.125 & Rp. 302.521 & Rp. - & $2 \%$ & Rp. $605.042,50$ \\
\hline 28 & $25 / 11 / 2018$ & HMP & Rp. 55.378.890 & Rp. 553.789 & Rp. 528.000 & $2 \%$ & Rp. 10.560 \\
\hline 29 & $15 / 11 / 2018$ & $3 \mathrm{SS}$ & Rp. 26.249.171 & Rp. 262.491,72 & Rp. - & $2 \%$ & Rp. 524.983,43 \\
\hline 30 & $19 / 11 / 2018$ & $3 \mathrm{SS}$ & Rp. 14.326 .800 & Rp. 143.268 & Rp. - & $2 \%$ & Rp. 286.536 \\
\hline
\end{tabular}


AKUNTOTEKNOLOGI : JURNAL ILMIAH AKUNTANSI DAN TEKNOLOGI - VOL. 11. NO. 1 (2019)

Versi Online Tersedia di : https://jurnal.ubd.ac.id/index.php/akunto

| 2085-8108 (Cetak) | 2541-3503 (Online) |

\begin{tabular}{|c|c|c|c|c|c|c|c|}
\hline 31 & $21 / 11 / 2018$ & $3 \mathrm{SS}$ & Rp. 13.442.720 & Rp. $134.427,20$ & Rp. - & $2 \%$ & Rp. 268.854.40 \\
\hline 32 & $23 / 11 / 2018$ & $3 \mathrm{SS}$ & Rp. 24.735.800 & Rp. 247,358 & Rp. - & $2 \%$ & Rp. 494.716 \\
\hline 33 & $29 / 11 / 2018$ & $3 S S$ & Rp. 17.681.283,20 & Rp. $176.812,83$ & Rp. - & $2 \%$ & Rp. $353.625,66$ \\
\hline 34 & $12 / 11 / 2018$ & RMA & Rp. 56.810 .400 & Rp. 568.104 & Rp. 1.143.000 & $2 \%$ & Rp. 22.860 \\
\hline 35 & $01 / 12 / 2018$ & ATT & Rp. $12.163 .630,20$ & Rp. $121.636,30$ & Rp. - & $2 \%$ & Rp. $243.272,60$ \\
\hline 36 & $05 / 12 / 2018$ & ATT & Rp. 39.630.050 & $\begin{array}{l}\text { Rp. } 396.300,50 \\
\end{array}$ & Rp. - & $2 \%$ & Rp. 792.601 \\
\hline 37 & $02 / 12 / 2018$ & HMP & Rp. 74.756.370 & Rp. 747.563 & Rp. 714.000 & $2 \%$ & Rp. 14.280 \\
\hline 38 & $04 / 12 / 2018$ & HMP & Rp. 36.533 .750 & Rp. 365.338 & Rp. 305.000 & $2 \%$ & Rp. 6.100 \\
\hline 39 & $09 / 12 / 2018$ & HMP & Rp. 56.889.500 & Rp. 568.895 & Rp. 542.500 & $2 \%$ & Rp. 10.850 \\
\hline 40 & $10 / 12 / 2018$ & HMP & Rp. 12.911 .700 & Rp. 129.117 & Rp. 372.000 & $2 \%$ & Rp. 7.440 \\
\hline 41 & $16 / 12 / 2018$ & HMP & Rp. 60.848 .340 & Rp. 608,483 & Rp. 580.500 & $2 \%$ & Rp. 11.610 \\
\hline 42 & $18 / 12 / 2018$ & HMP & Rp. 30.765 .000 & Rp. 307.650 & Rp. 250.000 & $2 \%$ & Rp. 5.000 \\
\hline 43 & $26 / 12 / 2018$ & HMP & Rp. 56.003.970 & Rp. 560.040 & Rp. 534.000 & $2 \%$ & Rp. 10.680 \\
\hline 44 & $27 / 12 / 2018$ & HMP & Rp. 11.748.720 & Rp. 117.487 & Rp. 378.000 & $2 \%$ & $\begin{array}{l}\text { Rp. } 7.560 \\
\end{array}$ \\
\hline 45 & $29 / 12 / 2018$ & HMP & Rp. 10.136.000 & Rp. 101.360 & Rp. 482.000 & $2 \%$ & Rp. 9.640 \\
\hline 46 & $03 / 12 / 2018$ & $3 \mathrm{SS}$ & Rp. 14.918.410 & Rp. $149.184,10$ & Rp. - & $2 \%$ & Rp. $298.368,20$ \\
\hline 47 & $11 / 12 / 2018$ & $3 \mathrm{SS}$ & Rp. 17.140.180 & Rp. $171.401,80$ & Rp. - & $2 \%$ & Rp. $342.803,60$ \\
\hline 48 & $14 / 12 / 2018$ & $3 \mathrm{SS}$ & Rp. 24.922.600 & Rp. 249.226 & Rp. - & $2 \%$ & Rp. 498.452 \\
\hline 49 & $15 / 12 / 2018$ & $3 \mathrm{SS}$ & Rp. 16.832 .900 & Rp. 168.329 & Rp. - & $2 \%$ & Rp. 336.658 \\
\hline 50 & $19 / 12 / 2018$ & $3 \mathrm{SS}$ & Rp. 46.470 .600 & Rp. 464.706 & Rp. - & $2 \%$ & Rp. 929.412 \\
\hline 51 & $21 / 12 / 2018$ & $3 \mathrm{SS}$ & Rp. 27.497 .445 & Rp. $274.974,45$ & Rp. - & $2 \%$ & Rp. 549.948,90 \\
\hline 52 & $13 / 12 / 2018$ & RMA & Rp. 64.606.700 & Rp. 646.067 & Rp. 1.342 .500 & $2 \%$ & Rp. 26.850 \\
\hline 53 & $06 / 01 / 2019$ & HMP & Rp. 37.905 .020 & Rp. 379.050 & Rp. 351.500 & $2 \%$ & Rp. 7.030 \\
\hline 54 & $07 / 01 / 2019$ & HMP & Rp. 7.892.037 & Rp. 78.920 & Rp. 316.000 & $2 \%$ & Rp. 6.320 \\
\hline 55 & $07 / 01 / 2019$ & HMP & Rp. 25.589 .400 & Rp. 255.894 & Rp. 346.000 & $2 \%$ & Rp. 6.920 \\
\hline 56 & $08 / 01 / 2019$ & HMP & Rp. 47.721 .025 & Rp. 477.210 & Rp. 398.500 & $2 \%$ & Rp. 7.970 \\
\hline 57 & $13 / 01 / 2019$ & HMP & Rp. 52.053 .370 & Rp. 520.534 & Rp. 484.000 & $2 \%$ & Rp. 9.680 \\
\hline 58 & $15 / 01 / 2019$ & HMP & Rp. 52.853 .500 & Rp. 528.535 & Rp. 357.500 & $2 \%$ & Rp. 7.150 \\
\hline 59 & $20 / 01 / 2019$ & HMP & Rp. 35.342 .300 & Rp. 353.423 & Rp. 327.500 & $2 \%$ & Rp. 6.550 \\
\hline 60 & $22 / 01 / 2019$ & HMP & Rp. 42.989 .697 & Rp. 429.897 & Rp. 457.500 & $2 \%$ & Rp. 9.150 \\
\hline 61 & $27 / 01 / 2019$ & HMP & Rp. 32.459 .240 & Rp. 324.592 & Rp. 300.500 & $2 \%$ & Rp. 6.010 \\
\hline 62 & $29 / 01 / 2019$ & HMP & Rp. 38.149.025 & Rp. 381.490 & Rp. 318.500 & $2 \%$ & Rp. 6.370 \\
\hline 63 & $07 / 01 / 2019$ & $3 \mathrm{SS}$ & Rp. 28.836.900 & Rp. 288.369 & Rp. - & $2 \%$ & Rp. 576.738 \\
\hline 64 & $08 / 01 / 2019$ & $3 \mathrm{SS}$ & Rp. 15.462.670 & Rp. $154.626,70$ & Rp. - & $2 \%$ & Rp. $309.253,40$ \\
\hline 65 & $16 / 01 / 2019$ & $3 \mathrm{SS}$ & Rp. 45.109.800 & Rp. 451.098 & Rp. - & $2 \%$ & Rp. 902.196 \\
\hline 66 & $17 / 01 / 2019$ & $3 \mathrm{SS}$ & Rp. 21.430.375 & Rp. $214.303,75$ & Rp. - & $2 \%$ & Rp. $428.607,50$ \\
\hline 67 & $19 / 01 / 2019$ & $3 \mathrm{SS}$ & Rp. 17.517.500 & Rp. 175.175 & Rp. - & $2 \%$ & Rp. 350.350 \\
\hline 68 & $23 / 01 / 2019$ & $3 \mathrm{SS}$ & Rp. 26.671.045 & Rp. $266.710,45$ & Rp. - & $2 \%$ & Rp. 533.420,90 \\
\hline 69 & $29 / 01 / 2019$ & $3 \mathrm{SS}$ & Rp. 20.186 .185 & Rp. $201.861,85$ & Rp. - & $2 \%$ & Rp. $403.723,70$ \\
\hline 70 & $30 / 01 / 2019$ & $3 \mathrm{SS}$ & Rp. 38.872.800 & Rp. 388.728 & Rp. - & $2 \%$ & Rp. 777.456 \\
\hline 71 & $31 / 01 / 2019$ & $3 \mathrm{SS}$ & Rp. 27.631.285 & Rp. $276.312,85$ & Rp. - & $2 \%$ & Rp. 552.625,70 \\
\hline 72 & $11 / 01 / 2019$ & RMA & Rp. 48.890 .645 & Rp. 488.906 & Rp. 1.045 .500 & $2 \%$ & Rp. 20.910 \\
\hline
\end{tabular}

Tabel di atas menunjukkan perhitungan pajak penghasilan pasal 23 atas jasa perantara atau keagenan (freight forwarder) pada PT. Banyu Biru Sentosa. Perusahaan melakukan pemotongan besarnya pajak penghasilan pasal 23 atas jasa perantara atau keagenan (freight forwarder). Dalam perhitungan diatas perusahaan belum menggunakan aplikasi eSPT. Perusahaan dalam perhitungan besarnya potongan pajak penghasilan pasal 23 atas jasa perantara atau keagenan (freight forwarder) masih manual dan komputerisasi yaitu dengan menggunakan kalkulator dan microsoft exel.

\section{A. Pemotongan Pajak Penghasilan Pasal 23 atas Pengunaan Jasa Perantara atau Keagenan (Freight Forwarder) pada PT. Banyu Biru Sentosa.}

\begin{tabular}{|c|c|c|c|}
\hline Masa Pajak & Nama Agen (PT.) & $\begin{array}{l}\text { Pemotong PPh Pasal } \\
\qquad 23\end{array}$ & $\begin{array}{l}\text { PPh Pasal } 23 \text { yang } \\
\text { dipotong }\end{array}$ \\
\hline \multirow{4}{*}{ Oktober 2018} & $\begin{array}{l}\text { PT. Perishable Logistic } \\
\text { Indonesia }\end{array}$ & \multirow{4}{*}{ PT. Banyu Biru Sentosa } & Rp. 6.298 .083 \\
\hline & PT. Hero Mitra Persada & & Rp. 4.397.062 \\
\hline & PT. Tiga Sekawan Sukses & & Rp. 852.812 \\
\hline & PT. Rubin Mitra Abadi & & Rp. 114.570 \\
\hline
\end{tabular}




\begin{tabular}{|c|c|c|c|}
\hline \multirow{4}{*}{ November 2018} & $\begin{array}{l}\text { PT. Perishable Logistic } \\
\text { Indonesia }\end{array}$ & \multirow{4}{*}{ PT. Banyu Biru Sentosa } & Rp. 3.428.992 \\
\hline & PT. Hero Mitra Persada & & Rp. 615.602 \\
\hline & PT. Tiga Sekawan Sukses & & Rp. 1.928 .714 \\
\hline & PT. Rubin Mitra Abadi & & Rp. 22.860 \\
\hline \multirow{4}{*}{ Desember 2018} & $\begin{array}{l}\text { PT. Perishable Logistic } \\
\text { Indonesia }\end{array}$ & \multirow{4}{*}{ PT. Banyu Biru Sentosa } & Rp. 1.035 .873 \\
\hline & PT. Hero Mitra Persada & & Rp. 83.160 \\
\hline & PT. Tiga Sekawan Sukses & & Rp. 2.955.641 \\
\hline & PT. Rubin Mitra Abadi & & Rp. 26.850 \\
\hline \multirow{3}{*}{ Januari 2019} & PT. Hero Mitra Persada & \multirow{3}{*}{ PT. Banyu Biru Sentosa } & Rp. 73.150 \\
\hline & PT. Tiga Sekawan Sukses & & Rp. 3.100 .564 \\
\hline & PT. Rubin Mitra Abadi & & Rp. 20.910 \\
\hline \multicolumn{3}{|c|}{ Total Pemotongan } & Rp. 24.954.843 \\
\hline
\end{tabular}

Dari tabel pemotongan pajak penghasilan pasal 23 atas penggunaan jasa perantara atau keagenan dapat disimpulkan bahwa perusahaan telah berperan sebagai pemotong Pajak Penghasilan Pasal 23 atas jasa perantara atau keagenan (freight forwarder).

B. Pelaporan Pajak Penghasilan Pasal 23 atas Pengunaan Jasa Perantara atau Keagenan (Freight Forwarder) pada PT. Banyu Biru Sentosa.

\begin{tabular}{|c|c|c|c|c|}
\hline Masa Pajak & Nama Agen (PT.) & $\begin{array}{l}\text { Bukti Potong PPh } \\
\text { Pasal 23 }\end{array}$ & Tanggal Pelaporan & Nilai Keterlambatan \\
\hline \multirow{5}{*}{ Oktober 2018} & $\begin{array}{l}\text { PT. Perishable Logistic } \\
\text { Indonesia }\end{array}$ & Rp. 1.328.889 & 11 November 2018 & Rp. 26.577 \\
\hline & $\begin{array}{l}\text { PT. Perishable Logistic } \\
\text { Indonesia }\end{array}$ & Rp. 4.969.194 & 05 Maret 2019 & Rp. 397.535 \\
\hline & PT. Hero Mitra Persada & Rp. 4.397.062 & 11 November 2018 & Rp. 87.941 \\
\hline & PT. Tiga Sekawan Sukses & Rp. 852.812 & 11 November 2018 & Rp. 17.056 \\
\hline & PT. Rubin Mitra Abadi & Rp. 114.750 & 06 Maret 2019 & Rp. 9.180 \\
\hline \multirow{5}{*}{$\begin{array}{l}\text { November } \\
2018\end{array}$} & $\begin{array}{ll}\text { PT. Perishable } & \text { Logistic } \\
\text { Indonesia } & \\
\end{array}$ & Rp. 3.428.992 & 05 Maret 2019 & Rp. 205.739 \\
\hline & PT. Hero Mitra Persada & Rp. 605.042 & 11 Januari 2019 & Rp. 24.201 \\
\hline & PT. Hero Mitra Persada & Rp. 10.560 & 05 Maret 2019 & Rp. 633 \\
\hline & PT. Tiga Sekawan Sukses & Rp. 1.080 .373 & 11 Januari 2019 & Rp. 43.214 \\
\hline & PT. Rubin Mitra Abadi & Rp. 22.860 & 11 Januari 2019 & Rp. 914 \\
\hline \multirow{4}{*}{$\begin{array}{l}\text { Desember } \\
2018\end{array}$} & $\begin{array}{ll}\text { PT. Perishable } & \text { Logistic } \\
\text { Indonesia } & \\
\end{array}$ & Rp. 1.035 .873 & 05 Maret 2019 & Rp. 41.434 \\
\hline & PT. Hero Mitra Persada & Rp. 83.160 & 05 Maret 2019 & Rp. 3.326 \\
\hline & PT. Tiga Sekawan Sukses & Rp. 2.955.641 & 05 Maret 2019 & Rp. 118.225 \\
\hline & PT. Rubin Mitra Abadi & Rp. 26.850 & 11 Januari 2019 & Rp. 537 \\
\hline \multirow{3}{*}{ Januari 2019} & PT. Hero Mitra Persada & Rp. 73.150 & 11 Januari 2019 & Rp. 1.463 \\
\hline & PT. Tiga Sekawan Sukses & Rp. 3.100.564 & 11 Januari 2019 & Rp. 62.011 \\
\hline & PT. Rubin Mitra Abadi & Rp. 20.910 & 11 Januari 2019 & Rp. 418 \\
\hline & Total & Rp. 24.106.682 & & Rp. 1.010.404 \\
\hline
\end{tabular}

Dari hasil tabel pelaporan pajak penghasilan pasal 23 atas jasa perantara atau keagenan (freight forwarder) yang terdapat di PT. Banyu Biru Sentosa bahwa pelaporan yang dilakukan perusahaan masih belum sesuai dengan peraturan perpajakan yang berlaku. Perusahaan sering kali melakukan pelaporan pajak penghasilan pasal 23 setelah tanggal 20 bulan berikutnya dikarenakan dari pihak masing-masing penyedia jasa perantara atau keagenan terlalu lama dalam menyerahkan faktur pajak.

\section{PEMBAHASAN}

A. Perhitungan Pajak Penghasilan Pasal 23 atas Jasa Perantara atau Keagenan (Freight Forwarder) pada PT. Banyu Biru Sentosa.

Untuk pencatatan dan perhitungan Pajak Penghasilan pasal 23 yang dilakukan oleh PT. Banyu Biru Sentosa adalah dengan menghitung secara manual kedalam microsoft excel serta melakukan penginputan data tersebut kedalam sistem e-SPT sehingga dapat melakukan pengecekan kembali apabila terdapat data yang tidak sesuai dengan yang 
dimiliki atau di input ke dalam sistem. Tarif yang digunakan dalam proses perhitungan Pajak Penghasilan pasal 23 yaitu sebesar $2 \%$.

B. Pemotongan Pajak Penghasilan Pasal 23 atas Pengunaan Jasa Perantara atau Keagenan (Freight Forwarder) pada PT. Banyu Biru Sentosa.

Untuk Pemotongan Pajak Penghasilan pasal 23 yang dilakukan oleh PT. Banyu Biru Sentosa masih belum sesuai dengan peraturan perpajakan yang ada, dikarenakan masih terdapat ketidaksesuaian besarnya potongan yang diterapkan oleh pihak penyedia jasa perantara atau keagenan. Besarnya jumlah pemotongan Pajak penghasilan pasal 23 yang diterapkan PT. Banyu Biru Sentosa ialah berasal dari 2\% atas dasar pengenaan pajak (DPP) dan juga $2 \%$ atas jasa yang diberikan oleh pihak penyedia jasa perantara atau keagenan, sehingga kesan yang ditimbulkan pada kasus ini tidak konsisten.

C. Pelaporan Pajak Penghasilan Pasal 23 atas Pengunaan Jasa Perantara atau Keagenan (Freight Forwarder) pada PT. Banyu Biru Sentosa.

Untuk Pelaporan Pajak Penghasilan pasal 23 yang dilakukan oleh PT. Banyu Biru Sentosa masih belum sesuai dengan peraturan perpajakan yang ada dikarenakan masing-masing penyedia jasa perantara atau keagenan sering terlambat dalam memberikan faktur pajak terkait dengan invoice yang telah di berikan kepada PT. Banyu Biru Sentosa sehingga mengakibatkan keterlambatan dalam melakukan pelaporan ke Kantor Pelayanan Pajak (KPP) Kebayoran Lama.

\section{KESIMPULAN}

1. Pelaksanaan pencatatan dan perhitungan Pajak Penghasilan Pasal 23 atas jasa perantara atau keagenan (freight forwarder) yang dilakukan di PT. Banyu Biru Sentosa menggunakan gabungan metode antara sistem manual dan komputerisasi yang saling berhubungan dengan baik untuk melakukan kewajiban perpajakan.

2. Besarnya potongan Pajak Penghasilan Pasal 23 atas jasa perantara atau keagenan (freight forwarder) sebesar $2 \%$ dari penghasilan bruto masih ada yang belum sesuai dengan peraturan perpajakan Undang-Undang Nomor 36 Tahun 2008. PT. Banyu Biru Sentosa dalam perhitungan pajak masih terjadi kesalahan dalam menetapkan perhitungan untuk melakukan pemotongan Pajak Penghasilan pasal 23 untuk beberapa jasa keagenan seperti yang terjadi pada PT. Perishable Logistic Indonesia (ATT), PT. Hero Mitra Persada (HMP), dan PT. Tiga Sekawan Sukses (3SS) periode Oktober 2018. Namun untuk PT. Hero Mitra Persada sendiri terdapat perubahan dalam penerapan perhitungan dan pemotongan Pajak Penghasilan Pasal 23 per tanggal 25 November 2018 sampai dengan saat ini (sudah sesuai dengan peraturan perpajakan). Untuk PT. Perishable Logistic Indonesia (ATT) dan PT. Tiga Sekawan Sukses (3SS) masih menerapkan metode perhitungan dan pemotongan Pajak Penghasilan Pasal 23 yaitu sebesar $2 \%$ dari jumlah dasar pengenaan pajak (DPP) sehingga pemotongan ini bertentangan dengan peraturan perpajakan Undang-Undang Nomor 36 Tahun 2008 yaitu sebesar $2 \%$ dari jasa yang diberikan oleh pihak penyedia jasa perantara atau keagenan (freight forwarder).

3. PT. Banyu Biru Sentosa telah berperan sebagai pemotong Pajak Penghasilan Pasal 23 atas jasa perantara atau keagenan (freight forwarder), sebagaimana perusahaan yang memakai jasa tenaga kerja tersebut sesuai dengan peraturan perpajakan di Indonesia.

4. Dalam hal pelaporan Pajak Penghasilan Pasal 23 atas jasa perantara atau keagenan (freight forwarder) yang dilakukan PT. Banyu Biru Sentosa sebagai pemotong Pajak, melakukan pelaporan ke kantor pelayanan pajak (KPP) Kebayoran Lama PT. Banyu Biru Sentosa terdaftar dengan menggunakan Surat Setoran Elektronik (SSE) masa 
Pajak Penghasilan Pasal 23 tidak tepat waktu. Dikarenakan terdapat kendala terhadap masing masing jasa keagenan dalam hal penyerahan faktur pajak ke PT. Banyu Biru Sentosa.

\section{DAFTAR PUSTAKA}

Abuyamin, Oyok. Perpajakan Dasar-Dasar Perpajakan; KUH; PPh; PPN \& PPn BM; PBB; BM; Pajak Daerah dan Retribusi Daerah; PPSP; Pengadilan Pajak; Pengatar Perpajakan Internasional. Bandung: Mega Rancage Press, 2015.

Chomariah, Wahyu Siti. "Analisis Perhitungan dan Pelaporan SPT Masa Desember PPH Pasal 23 Pada PT. Pelabuhan Indonesia IV (Persero) Cabang Samarinda." Jurnal Akuntansi, 2017: 62-63.

Damayanti, Supramono Theresia Woro. Perpajakan Indonesia Mekanisme dan Perhitungan. Yogyakarta: Andi, 2015.

Daulay, Septi Riska. Analisis Perhitungan, Pemotongan, dan Pelaporan Pajak Penghasilan Pasal 23 Pada PT. Heat Exchangers Indonesia. Batam: Politeknik Negeri Batam, 2013

Hartati, Neneng. Pengantar Perpajakan. Bandung: CV. Pustaka Setia, 2015.

Kasirin. Perpajakan Indonesia. Serang: Dinas Pendidikan Provinsi Banten, 2012.

Mardiasmo. Perpajakan Edisi Terbaru 2016. Yogyakarta: Andi, 2016.

Moleong. Metode Penelitian Kualitatif Edisi Revisi. Bandung: PT. Remaja Ros, 2014.

Nurdin Hidayat, dan Dedi Purwana. Perpajakan Teori dan Praktik. Jakarta: PT. Raja Grafindo Persada, 2017.

Parengkuan, Angelika, Jantje J. Tinangon, dan Inggriani Elim. "Analisis Perhitungan dan Pelaporan PPH Pasal 23 Pada Perum Bulog Divre Sulut dan Gorontalo." Jurnal EMBA, 2014: 9.

Peraturan Direktur Jenderal Pajak No. PER-178/PJ/2006. Tentang Jenis Jasa Lain dan Perkiraan Penghasilan Netto Sebagaimana Dimaksud Dalam Pasal 23 Ayat (1) Huruf c Undang-Undang No. 7 Tahun 1983 Tentang Pajak Penghasilan Sebagaimana Telah Diubah Terakhir Dengan Undang-Undang No. 17 Tahun 2000. n.d.

Pertiwi, Intan Rahayuning. Analisis Perhitungan, Pemotongan, Dan Pelaporan PPH 23 Atas Jasa Service Pada PT. UNISEM Batam. BATAM: POLITEKNIK NEGERI BATAM, 2014.

Resmi. Perpajakan Teori dan Kasus. Jakarta: Salemba Empat, 2016.

- Perpajakan; Teori dan Kasus. Jakarta: Salemba Empat, 2012.

Stephanie, Gesha Violensia. "Analisa Pajak Penghasilan Pasal 22 Terhadap Pembelian Impor Pada PT. Adi Buana Mandiri." Skripsi, 2016.

Suandy, Erly. Hukum Pajak. Jakarta: Salemba Empat, 2011.

Sugiyono. Metode Penelitian Kuantitatif Kualitatif dan Kombinasi (Mixed Mehods). Bandung: Alfabeta, 2016.

-. Metodologi Penelitian Kualitatif, Kuantitatif, dan R\&D. Bandung: Alfabeta, 2016.

Surat Edaran No. SE-53/PJ/2009. Tentang Jumlah Bruto Sebagaimana Dimaksud Dalam Pasal 23 Ayat (1) Huruf C Angka 2 Undang-Undang No. 7 Tahun 1983 Tentang Pajak Penghasilan Sebagaimana Telah Beberapa Kali Diubah Terakhir Dengan Undang-Undang No. 36 Tahun 2008. n.d.

Susyanti Jeni, dan Dahlan Ahmad. Perpajakan Untuk Praktisi dan Akademisi. Malang: Empatdua Media, 2015.

Tinangon, Cisilia, David Paul Elia Saerang dan Inggriani Elim. "Analisis Perhitungan, Pencatatan, dan Pelaporan Pajak Penghasilan 23 Atas Pengadaan Barang Dalam Hal ini Jasa Penyewaan Barang Berat Pada PT. William Makmur Perkasa." Jurnal Akuntansi, 2014: 7. 
AKUNTOTEKNOLOGI : JURNAL ILMIAH AKUNTANSI DAN TEKNOLOGI - VOL. 11. No. 1 (2019)

Versi Online Tersedia di : https://jurnal.ubd.ac.id/index.php/akunto

$$
\text { | 2085-8108 (Cetak) | 2541-3503 (Online) | }
$$

Undang-Undang No.7 Tahun 1983. Tentang Ketentuan Umum dan Tata Cara Perpajakan Sebagaimana Telah Beberapa Kali Diubah Terakhir Dengan Undang-Undang No. 36 Tahun 2008. n.d.

Walandouw, Patric. "ANALISIS PERHITUNGAN DAN PELAPORAN PPH PASAL 23 DAN PPH PASAL 25 PADA CV. MITRA JAYA LESTARI." Jurnal Akuntansi, 2013: 996.

Waluyo. Perpajakan Indonesia. Jakarta: Salemba Empat, 2011. 